Article

\title{
Bridging the Gaps for a 'Circular' Bioeconomy: Selection Criteria, Bio-Based Value Chain and Stakeholder Mapping
}

\author{
Kadambari Lokesh ${ }^{1, *}$, Luana Ladu ${ }^{2}$ and Louise Summerton ${ }^{1}$ \\ 1 Green Chemistry Centre of Excellence, University of York, York YO10 5DD, UK; \\ louise.summerton@york.ac.uk \\ 2 Faculty of Economics and Management, Technische Universität Berlin, Sekr. MAR 2-5, Marchstraße 23, \\ 10587 Berlin, Germany; luana.ladu@tu-berlin.de \\ * Correspondence: kadambari.lokesh@york.ac.uk
}

Received: 20 April 2018; Accepted: 14 May 2018; Published: 23 May 2018

\begin{abstract}
Bio-products and bio-based value chains have been identified as one of the most promising pathways to attaining a resource-efficient circular economy. Such a "valorization and value-addition" approach incorporates an intricate network of processes and actors, contributing to socio-economic growth, environmental benefits and technological advances. In the present age of limited time and funding models to achieve ambitious sustainable development targets, whilst mitigating climate change, a systematic approach employing two-tier multi-criteria decision analysis (MCDA) can be useful in supporting the identification of promising bio-based value chains, that are significant to the EU plans for the bio-economy. Their identification is followed by an elaborate mapping of their value chains to visualize/foresee the strengths, weaknesses, opportunities and challenges attributable to those bio-based value chains. To demonstrate this methodology, a systematic review of 12 bio-based value chains, prevalent in the EU, sourcing their starting material from biomass and bio-waste, has been undertaken. The selected value chains are mapped to visualize the linkages and interactions between the different stages, chain actors, employed conversion routes, product application and existing/potential end-of-life options. This approach will help chain-actors, particularly investors and policy-makers, understand the complexities of such multi-actor systems and make informed decisions.
\end{abstract}

Keywords: value chain; multi-criteria decision analysis; circular economy; value chain-mapping; bioeconomy

\section{Introduction}

Escalating environmental and economic pressure to use our resources responsibly and add value to the used material/products in the commercial sphere has helped the development of technology routes and material circularity in nearly every global sector. According to the EU Circular Economy Strategy, the aim of such systems thinking is to "close the loop by becoming resource efficient through development and establishment of industrial symbiosis, to reduce the pressure on EU's natural capital" [1].

The approach to attaining/creating a circular economy is cascading of material, which may be virgin raw materials, by-products or wastes resulting from any given sector. The concept of cascading and its significance to the establishment and growth of a resource/energy efficient, green and low-carbon economy has been a recurring theme in EU policies since 2012, particularly in the EU Forest Strategy, EU Bioeconomy Strategy and EU Circular Economy package [2]. To understand the state of our transition, transparency on the EU-level biomass potential is essential. Bioeconomy, according to the European Commission, is a part of the economy that utilises bio-based renewable resources 
sourced both from land and sea, processed to produce materials and energy for consumption [3]. A fully-functional bioeconomy is one of the many pathways that have been identified to attaining a circular economy, both at micro-level (local rural development) and macro-level (nation-wide) [4]. The principles of both circular economy and bioeconomy are in synergy, in terms of the ultimate goal of attaining a sustainable technological and socio-economic development by decoupling economic growth from resource exhaustion and subsequent environmental degradation [5]. The two economies share a growing overlap, however, there is currently a need to push circularity down to the consumer level, which is where the largest share of waste is found with no end-of-life valorisation. This has been stated as one of the biggest challenges of the bioeconomy. However it is acknowledged that some sectors of the bioeconomy cannot satisfy the principles of circular economy (e.g., bioenergy and biofuel) because they are considered a dead end route for biomass [6]. In terms of current targets for sustainable growth, bioeconomy, in combination with circular economy, has the potential to directly contribute to 11 out of the 17 UN's Sustainability Development Goals (SDGs) (Figure 1). The direct contribution of circular and bio-based economy to sustainable consumption and production (SDG 12), reducing our pressure on the environment, air, water and land (SDG 13,14,15) is the ultimate aim of the concept. By working in partnership with rural communities and local bio-based infrastructure $[7,8]$ (SDG17), utilising the rural knowledge pool, alleviation of poverty (SDG 1 and 2), forging skills among communities (SDG 4) to take an interest in guarding the local ecosystem services encourages the development of sustainable communities (SDG11), in addition to creating jobs and socio-economic opportunities (SDG 8). Use of bioenergy, devising smart strategies and value-chain pathways to lock the chain's GHG emissions, either via carbon capture or soil incorporation of high quality biochar, have been identified as potential means of achieving the ambitious Paris climate target [9].
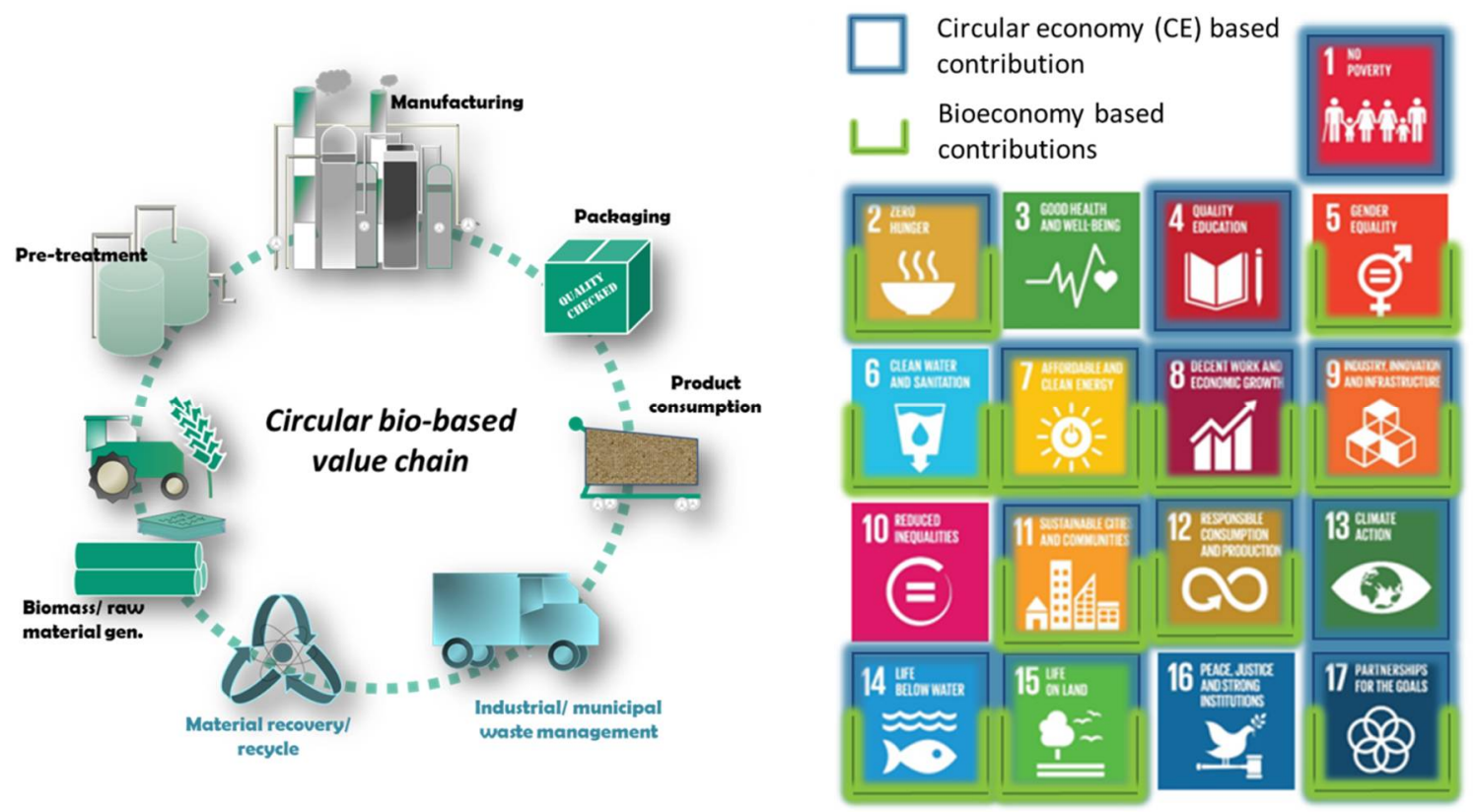

Figure 1. Potential for circular bio-based value chain to contribute to achieving UN's SDGs and the potential of value chain mapping and analysis in quantifying these goals.

Having comprehended the synergies between a circular economy and a bioeconomy and its potential for contributing to the global sustainability targets from a number of earlier studies [5,10], it is crucial to understand where we stand to take appropriate and smarter "next steps". Prior to exploring the opportunities that bioeconomy could offer, the probability of it being successfully established must also be systematically investigated. 
A methodical approach for the selection and mapping of the most promising circular bio-based value chain is presented in this paper. The purpose of the methodology expressed in this paper is to encourage innovative thought processes, within the chain-actors and other external stakeholders, on how to identify and focus precious resources and efforts in the development of multi-functional value chains and business models using a set of selection criteria, and to be able to foresee the complexities and performance needs of the value chain, thereby minimising risks and shocks to the conceptual process system. This approach is clearly missing, not only within the bio-based sector but also within industrial sectors that are gearing-up towards a transition to circularising their supply chains. The suggested methodology can, therefore, be adopted for application within non-bio-based value/supply chains as well. To demonstrate this methodology, some exemplary bio-based value chains have been selected from a pool of bio-based value chains that are prevalent in the EU. This study employs a two-tier multi-criteria decision analysis to identify these most promising value chains.

\subsection{Background}

A value-chain is defined as a set of interlinked activities that deliver products/services by adding value to bulk material (feedstock). In a bio-based value chain, the feedstocks tend to be biomass drawn from an existing primary production route (e.g., agriculture, forestry and livestock), or of a novel (e.g., microalgae) or secondary origin (e.g., sludge, industrial wastewater and household organic waste). A generalised schematic for an ideally circular bio-based value chain has been presented in Figure 2 .

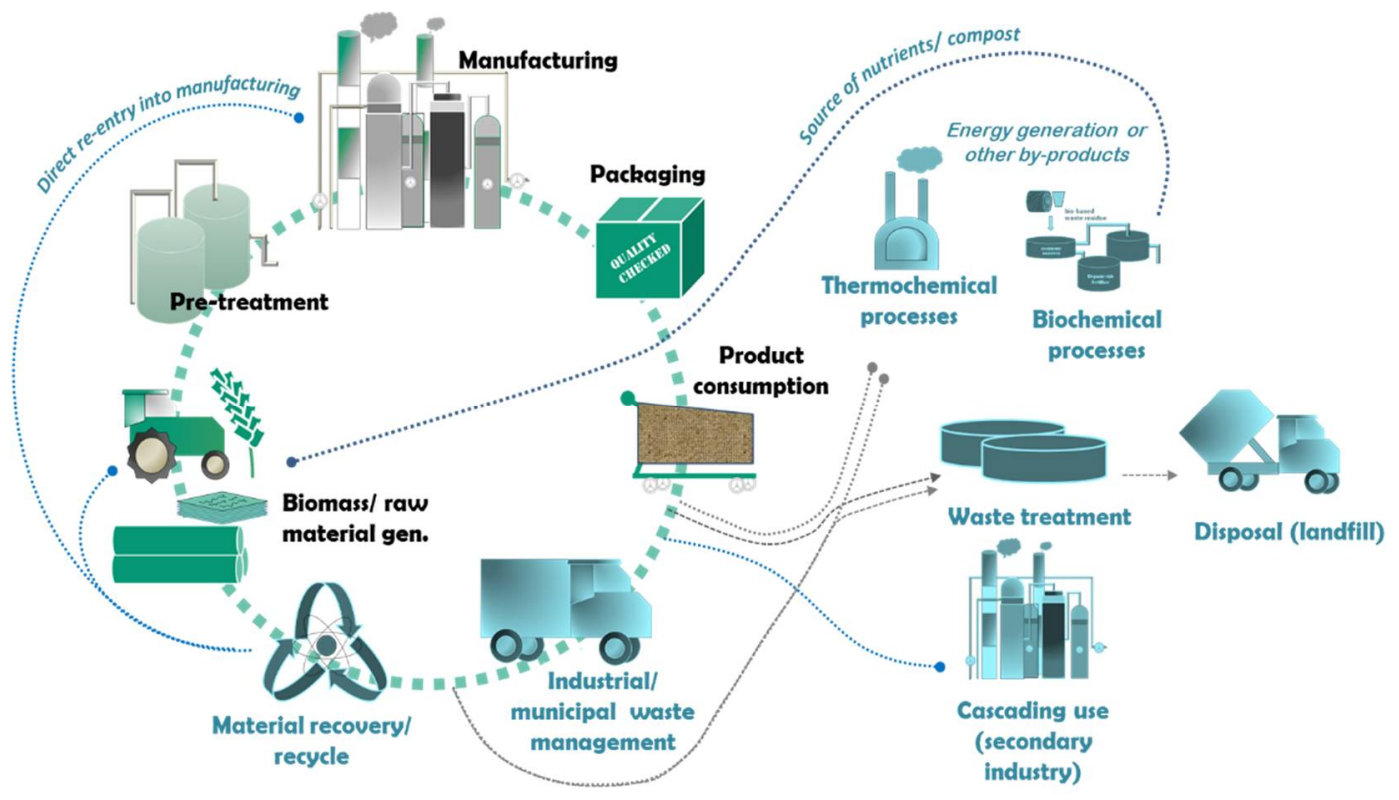

Figure 2. Figure 2. A generalised map of a bio-based value chain.

Value chains, in particular those that valorise secondary resources are designed to turn available organic material into different valuable product, ranging from high-value chemicals to secondary-use by-products and renewable energy [11]. Pathways that are capable of transforming waste/secondary feedstock into an array of high value products are called integrated biorefineries [12]. Integrated biorefineries contain a "pre-treatment plant" that prepares the feedstock for upcoming transformation and refining technologies within the supply chains, before packaging and distribution.

The first stage of a complex bio-based value chain is biomass availability. Brosowski et al. (2016) define the quantity of biomass, generated by a confined area of land (country) that is currently used or has the potential to be used as the "biomass potential" [13]. Biomass potential may be measured from a number of relevant sustainability-based angles: theoretical, environmental, economic and sustainable. Theoretical potential provides an estimation of potential biomass productivity based on 
the physical characteristics of all available arable land. Environmental and economic biomass potential, based on the fraction of the theoretical biomass potential, gradually adds land exclusions such as legally protected area, slopes, biodiversity richness and take into account the technical capability of the pre-existing biomass processing framework. Sustainability potential is the final filter that takes the technical, economic and environmental restrictions (and associated biomass capacities) into account providing the net estimated biomass production capacity for a given geographical location [14]. Focusing on EU biomass supply, the agricultural and forestry feedstock within the EU constitutes 1.13 billion tonnes of dry biomass [15]. From a stakeholder perspective, which draws data via engagement (interviews and survey questionnaire) with EU-based value chain actors, more than $40 \%$ of renewable material is invested in non-conventional industrial applications in EU-28. In such successful bio-based industries there are in-house developed frameworks for value-chain actors to communicate and synchronise their operations [15]. From the perspectives of bio-based industries, according to a 2016 study undertaken by the Joint Research Centre (JRC), European Commission, EU-28 has been determined to be home to 133 bio-based industries, excluding the relevant industrial research and development (R\&D) institutions [16]. Nevertheless, a survey undertaken by the Bio-based Industries Consortium (BIC) and Nova Institute [17], revealed 224 bio-based industries with biorefineries processing different types of feedstock, mapped across EU demonstrating a sharp growth, as presented in Figure 3.

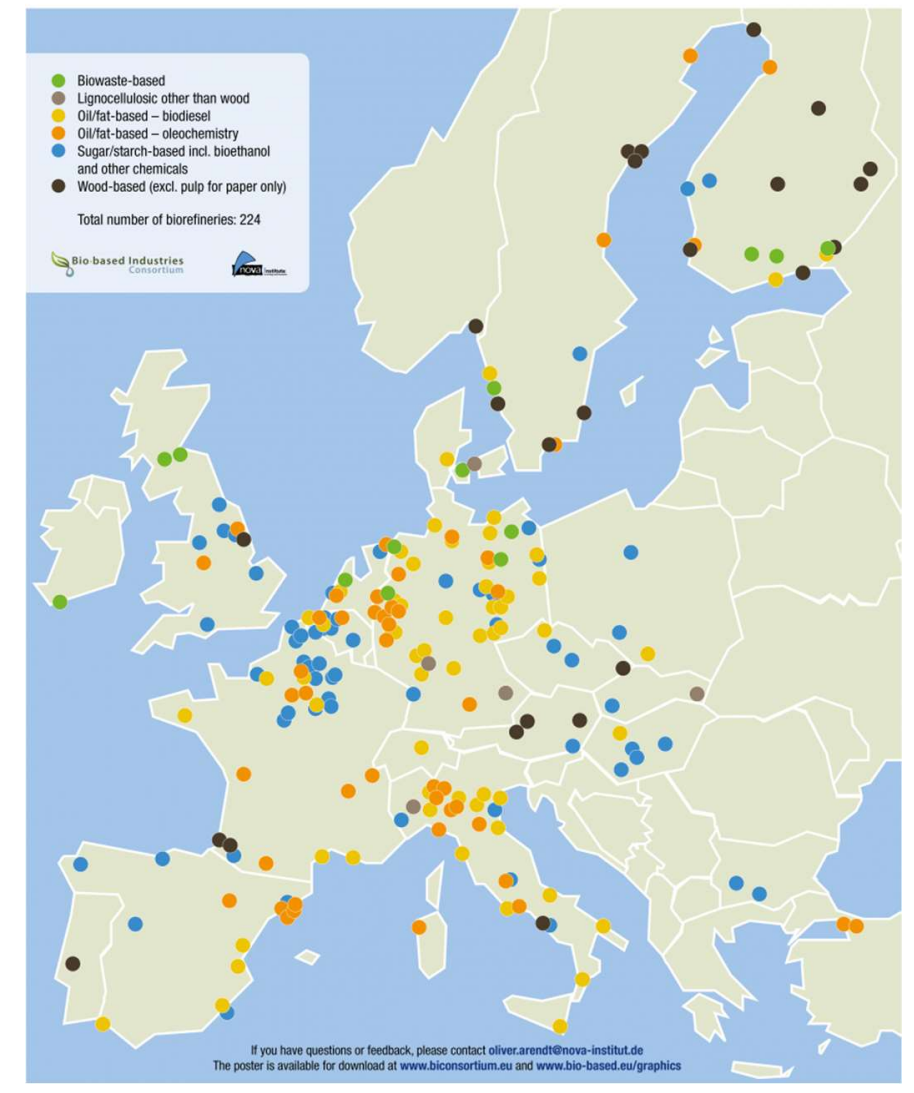

Figure 3. Biorefinery map in Europe (Source: [17]).

Long-term, innovative systems thinking which encourages the exploitation of organic waste/residues from agriculture, animal husbandry, domestic, industrial and commercial industries are exploited, is essential. Such solutions not only help gain access to and expand the innovation boundaries but also enable a systematic and feasible transition to a bioeconomy. Such a transition has been identified to benefit the economy through the creation of SMEs and skilled employment opportunities, in addition to reaching EU's climate change mitigation targets and to reduce dependence 
on fossil-derived resources [18]. With mounting pressure from a number of factors including limited time, finance, resources and impending environmental targets, the suggested method helps envisage the potential performance of any bio-based value chains. This is crucial to not only policy-makers, but also to any decision-making stakeholder in the value chain, in terms of material, financial, human resource allocation and operation $[19,20]$. From the socio-economic perspective, creation of a multi-regional/local value chain, networks, growth of SME's and other employment opportunities, development of waste-management infrastructure (where lacking), local skill-forging and knowledge dissemination are some of the practical benefits of a fully-functional bio-based value chain [21].

From a sectoral perspective, the EU biorefinery map (Figure 3) represents the prevalence of high numbers of oil and fat based biorefineries dedicated to the production of biofuel and oleochemical products.

\subsection{Bioeconomy Strategies Initiatives}

The primary policy framework of the European bioeconomy is represented by the European Bioeconomy Strategy and Action plan adopted by the EU in 2012 [22]. It provides policy framework conditions for developing new technologies and processes for the production and commercialization of renewable biological resources and their conversion into bio-based products. An ongoing revision of the bioeconomy strategy aims at establishing a more coherent and holistic policy and financial framework for the European bio-based economy, supporting access to sustainably produced biomass, fostering investments and further developing the commercialization of bio-based products. One important recommendation is to further develop the synergies and complementarities between EU policies and funding instruments with interconnected objectives with the bioeconomy. Among these policies, an important role is played by the circular economy strategy and by other sectorial policies that govern traditional sectors of the bioeconomy (e.g., the Common Agricultural Policy [CAP]).

However, from a value chain and bio-product perspective, a majority of current bioeconomy strategies are dedicated to bioenergy and biofuel-based value chains, followed by food and beverage chains. Prevalence of many such value chains may be attributed to the EU's race towards renewable energy consumption targets set in the Energy Strategy for 2030 [23]. However, a surge in integrated biorefineries that synthesise bio-based products other than biofuels is evident from the most recent report compiled and analysed from a stakeholder engagement approach undertaken by the Bio-based Industrial Consortium (BIC) and Nova Institute [17]. The growth of biomass-cascading biorefineries is also supplemented by the keenness of European bio-based industries to valorise organic-rich bio-waste (mainly agricultural residue and sludge). Besides, seizing an opportunity to synthesise value-added products from low-cost feedstock, an unhindered supply of starting material (one of the key barriers to bio-product synthesis), is a promising start for a bio-based business model. According to a study undertaken by Meyer-Kohlstock et al., (2015), the supply of biomass and waste for consumption within other value chains was predominantly sourced from the agri-food and livestock sector [24]. Though bio-based value chains create opportunities to circularise, some chain-level dynamics influence the environmental, commercial and social practicability of the same by varying degrees. These dynamic factors include biomass supply logistics, feedstock costs (influenced by whether the feedstock is primary or secondary), feedstock treatment requirements and ethical compliance requirements. Firstly, it is essential to identify a bio-based value chain with techno-economic potential, and that is environmentally and socio-economically sensible. Secondly, when developing a bio-based business model around the identified value chain, it is imperative to anticipate the various interactions among processes, stakeholders and related process-dynamics on the overall performance of the chain. The aim of this paper is to provide a two-fold methodology that helps identification of promising bio-based value chains and to demonstrate how value chain mapping can help stakeholders visualise the various interactions embedded in a value chain. Escalating environmental and economic pressure to use our resources responsibly and add value to the used material/products in the commercial sphere has helped the development of technology routes and material circularity, in nearly every global sector. 
According to the EU Circular Economy Strategy, the aim of such systems thinking is to "close the loop by becoming resource efficient through development and establishment of industrial symbiosis, to reduce the pressure on EU's natural capital" [1].

\section{Methodology}

\subsection{Value Chain Selection Criteria}

Multi-criteria decision analysis (MCDA) is a valuable tool for decision making in complex process systems using multiple parameters that influence the embedded processes within a value chain. These parameters can be differently weighed as "significant factors" by the various chain-actors. Also, incorporating this flexibility into the scope of this assessment, MCDA in decision making enables a systematic investigation and transparency in analysis [20]. The goal of MCDA, in general, is to provide an opportunity to explore the knowledge and concerns put forward by the chain-actors, weigh them from an unbiased viewpoint, systematically analyse, identify the most important criteria, and subsequently, make decisions within a complex multi-actor process systems. This study employs two-tier MCDA to rank bio-based value chains based on a set of selection criteria, highlighting the significance of their adherence to the principles of circular economy. The outcomes of this analysis highlight the importance of these selection criteria dedicated to highlighting the circularity characteristics of any bio-based value-chain/business model. An elaborated mapping methodology to understand the strengths, weaknesses, opportunities and challenges embedded in a bio-based value chain, attributable to the synthesis of a variety of bio-products, also demonstrating the significance of upstream processes and material use on the downstream activities (mainly post-consumption and end-of-life management) has been presented as a part of this paper. Please see Figure 4 for a flow diagram that elaborates the MCDA methodology employed in this study for value chain selection and mapping.

A variety of bio-based value chains have been identified to be prevalent in the EU and are presented in Table 1. This list of preliminary value chains was drawn from the literature review earlier, focusing on bio-based value chains/products covered by EU certification schemes and market demand [25]. The list comprises bio-based value chains with (but not limited to) diverse characteristics covering:

- From virgin food-based feedstock to bio-waste cascading;

- $100 \%$ bio-based to partially bio-based, value chains;

- Those with a fully-functional waste management infrastructure to those that lack one;

- Diverse product functionality.

Table 1. List of EU-based value chains considered for selection, analysis and mapping exercise.

\begin{tabular}{cl}
\hline Sector & \multicolumn{1}{c}{ Value Chain } \\
\hline Chemicals & Cellulose to bio solvents \\
Disposable food packaging & Starch to bioplastic food packaging \\
Agriculture & Starch to bio-based mulch films \\
Fabrication & Starch to bioplastics for fabrication \\
Automotive & Vegetable fats to bio lubricants \\
Agriculture/waste management & Solid biomass to fine chemicals \\
Textiles & Cellulose to fabric \\
Food packaging & Cellulose to plastic paper cups \\
Construction & Waste biomass to insulation material \\
Construction & Waste biomass to wood-plastic composites \\
Agriculture & Polysaccharides to crop health inducers \\
Animal husbandry & Plant-based chemicals to fine chemicals \\
\hline
\end{tabular}




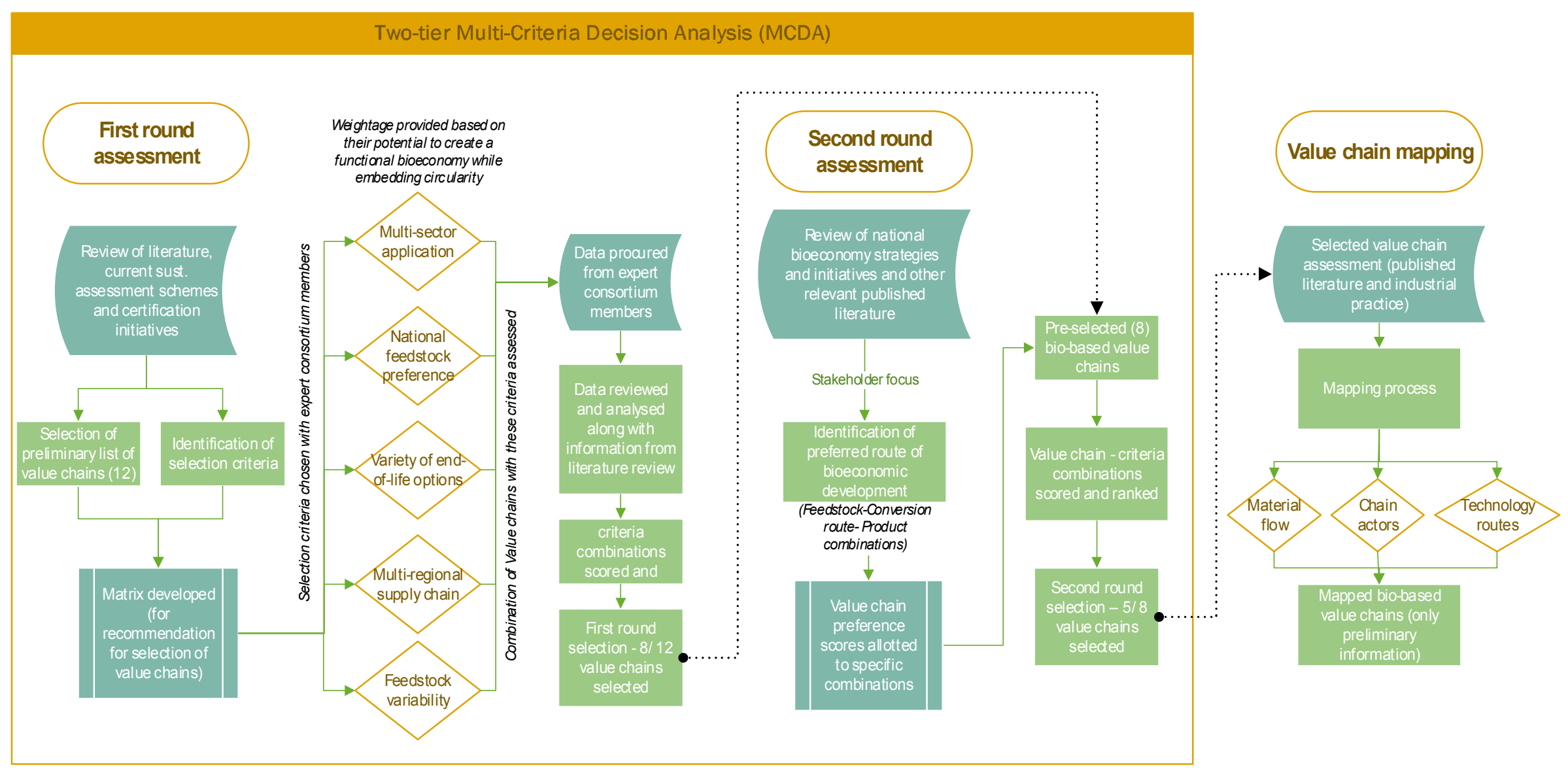

Figure 4. Flow diagram of the methodology involved in the two-tier multi-criteria decision analysis and mapping exercise adopted for the selection of the most promising bio-based value chains, in the context of a circular economy. 
For systematic identification of promising value chains, a multi-criteria selection approach was used. A set of selection criteria were chosen based on the gaps that were identified from review of published literature and policy. There are a number of different bio-based value chains prevalent in the EU. To identify those multi-functional value chains (perhaps under-represented), for example, those that integrate material circularity, utilising agricultural by-products/waste, capability to create better and wider socio-economic growth/employment opportunities and needing less or no further investment in the form of a dedicated infrastructure, it is essential to use a few key criteria. The performance of candidate value chains from the viewpoint of these selected criteria must be assessed in detail. This approach will help this study weigh the potential and resilience of these candidates in the commercial market, against the backdrop of the EU's bioeconomy policies and in our journey towards "closing the loop". The selection criteria chosen for the first-round assessment of bio-based value chains are presented in Figure 5. The rationale for choosing these selection criteria may be found under the respective descriptions in the upcoming segments.

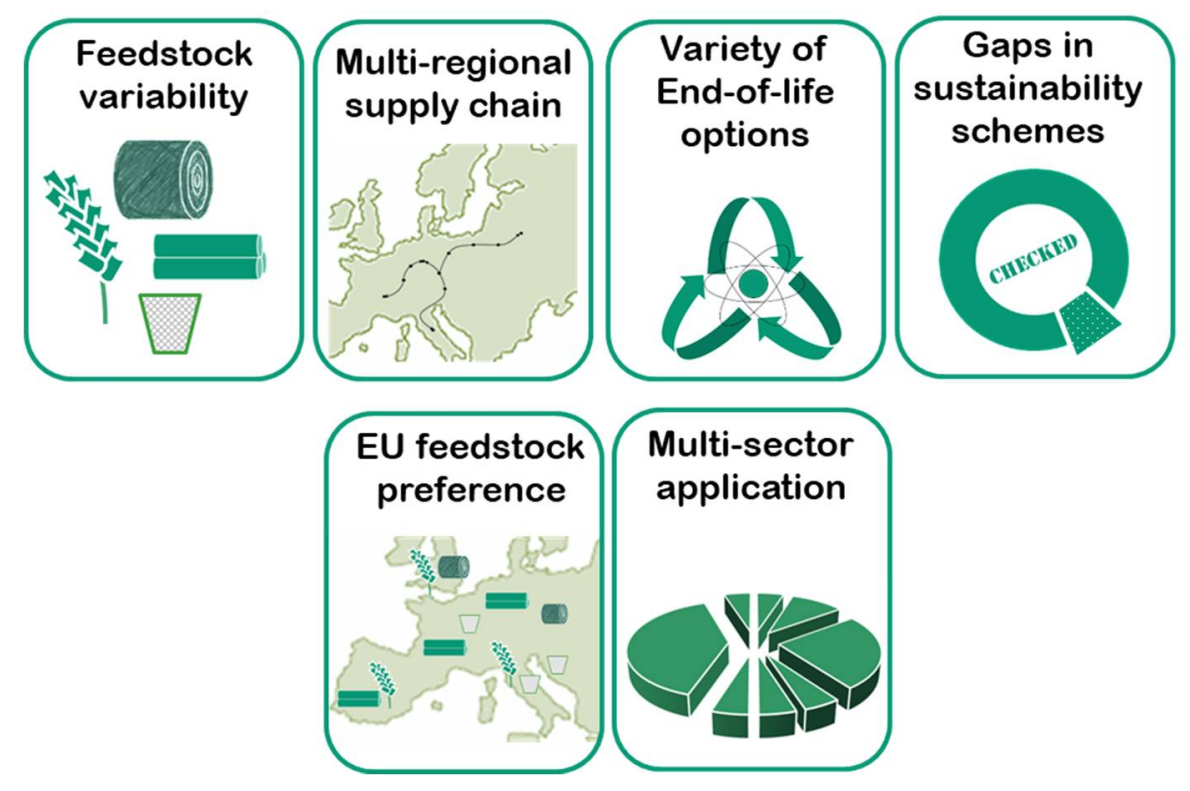

Figure 5. Selection criteria for the identification of the most promising bio-based value chains.

Feedstock variability: The flexibility of bio-based value chains to produce products and by-products from a variety of feedstocks is crucial. Biomass, the starting material of any bio-based value chain, is cost-susceptible to both market volatility and also seasonal in nature. Dependence on a seasonal feedstock will lead to a seasonal value chain, thereby resulting in seasonal products (and byproducts) which gives bio-based products a less attractive perspective among consumers [26].

Multi-regional supply chain: A multi-regional value chain, besides adding value to a low-value feedstock, also contributes to the economic growth of dependent communities via creation of jobs, development of skills and the knowledge pool of the local communities, leading to improved community wellbeing and social equity. Such approaches require a harmonised approach to reporting and communication of information among the embedded chain actors for transparency on practices and traceability of materials. However, such an approach could facilitate EU states with transition economies to establish bioeconomy models, with the needed investment from national funding initiatives [27].

Variety of end-of-life: End-of-life characteristics play a prominent role at any given stage of a value chain. From a top-down approach, a process that is capable of utilising waste biomass for raw feedstock, also called "cascading use" is a valuable, sustainable business model as there will a regular influx of low-cost feedstock, promising a continuous product supply to the market. From a 
"bottom-up" approach, strategic management and utilisation of waste (post-product consumption) is capable of delivering three-fold benefits: environmentally through reduction of waste for treatment and disposal; economically by enabling resource efficiency and through transformation of waste (as low-cost raw material for a secondary industry); and socially through creation of jobs, new value chains and social equity [28]. To be able to "catch up" with the 2014 EU Landfill Directive (which aims to phase out landfilling recyclable waste, e.g., bioplastics, paper, glass and bio-waste), we need to identify candidate value chains that generate products that can potentially circularise the value chain. Selection of value chains based on the capabilities of the products to demonstrate a variety of end-of life characteristics would be valuable to report via this study.

Gaps in sustainability schemes: From assessing the outcomes of the literature review, it is evident that sustainability schemes for bio-based products (e.g., bioplastics, bio-solvents, bio-based adhesives and binders, enzymes and cosmetics, etc. but not bioenergy) are either still in their infancy or have variable levels of maturity with major sustainability related gaps to cover. Some major gaps and limitations include a lack of clear criteria for sustainability / circularity assessment of bio-based products on one hand and on the other hand, an overlap in the existing certification schemes. For example, for the CEN standards for bioplastics (CEN/TC/249), some of the sustainability criteria such as the determination, declaration and reporting of the bio-based carbon content [29-32] are required via the following standards:

- CEN/TS 16137:2011: Plastics-Determination of bio-based carbon content

- CEN/TS 16295:2012: Plastics-Declaration of the bio-based carbon content

- CEN/TS 16398:2012: Plastics-Template for reporting and communication of bio-based carbon content and recovery options of biopolymers and bioplastics-Data sheet

However, these standards do not explicitly direct the economic operator to take further responsibility to address/quantify the sustainability criteria associated with bioplastics including production derived emissions to air, water and soil or economic and social impacts. A discrete set of standards is under development by the technical committee (CEN/TC/411) for bio-based products to report the sustainability aspects of bio-based products [33]. These standards are responsible for the determination, declaration and reporting of environmental impact assessment (e.g., EN16751: Bio-based products: sustainability criteria). The scope of EN16751 in particular, despite providing guidance on undertaking impact assessment and reporting on bio-based products, covers the stages from feedstock acquisition up to the feedstock "pre-processing" phase. Lack of guidance on assessment and reporting of environmental burden resulting from "manufacturing" to "end-of-life" phases, and lack of assessment methodologies and thresholds are some of the major gaps and limitations in these standards.

Country-based feedstock preference: Consistency in raw material supply and chain-productivity is essential for the successful uptake of bio-based products and their associated value chains. The guarantee of a promising flow of feedstock to the facilities can only be ensured through the choice of "locally sourced" feedstock. "Locally-sourced" feedstocks generally have established logistics and reporting procedures, which can communicate their point of origin to the economic operator. Moreover, utilisation of such "locally generated feedstock" can be associated with positive social impacts from employing decades of skilled cultivation related knowledge from the local rural community and its established infrastructure, catalysing its development with an innovative biorefinery, subsequently reducing the overall cost of value-chain establishment $[34,35]$.

Multi-sector application: The ability of a bio-based product and its value chain to cover a range of applications (in different industrial sectors) was identified as an important criterion for value chain selection. Undertaking this task for value chains with products that serve a rather smaller demand/specialised demand could make this study highly specific, deviating from the aim of creating a harmonised sustainability framework for horizontal sector application. Therefore, focus is placed on value chains and bio-based products that have the potential to be applied in a variety of sectors 
(e.g., bio-based mulch film catering to agricultural/horticulture industries and other industries like the landscaping industry; versatile fine chemicals that find application as solvents in paints and coating, adhesives and binders, fuel additives and agrochemicals).

\section{Application of These Value Chain Selection Factors with Multi-Criteria Decision Analysis}

First round assessment and selection: A dedicated matrix composed of a combination of the preliminary value chains which are to be assessed from the viewpoints of each of these selection criteria was developed as a part of this first-tier analysis. Since this study is a part of a project with a wider vision, the expertise of the consortium members in bioeconomy was invited. Their recommendations in terms of the performance of the set of preliminary value chains, in combination with the set of selection criteria, presented in Figure 5, was obtained and reviewed. Scores, in the form of rating (scale of 1-10), were allocated to the recommendations (yes/maybe/no) with justification provided by the consortium members.

Secondly, each of the selection criteria were allotted weighting factors based on their relevance and significance to the principles of material circularity and bioeconomy transition. The weighting factors are presented in Table 2. The criteria that have been allocated a weighting of 0.2 are those that directly contribute to innovative or under-represented but resource efficient value chains which subsequently have the potential to encourage the establishment of a circular economy. Criteria with a weighting of 0.1 (preference within EU member states) has been covered further with an elaborate evaluation under second round assessment. Relevant characteristics of each of the bio-based value chains were assessed and reviewed against the weighted selection criteria to finally assign ranks from the first round. The outcomes of the first round of assessment and further discussion on this approach to the identification of promising bio-based value chains have been presented in Section 3.1.

Table 2. Distribution of weighting to the "value-chain selection" criteria.

\begin{tabular}{cc}
\hline Selection Criteria & Weighting \\
\hline Feedstock variability & 0.2 \\
Gaps in certification/sustainability schemes & 0.2 \\
Multi-sector application & 0.15 \\
Variety in End-of-life options & 0.2 \\
Multi-regional supply chain & 0.15 \\
Preference within EU member states & 0.1 \\
\hline
\end{tabular}

Second round assessment and selection: The second round of assessment was initiated with the collation of information and analysis of national policies, bioeconomy initiatives and growth plans established by individual EU member states. This review provides an insight into the bioeconomy strategy adopted by individual states based on their strengths such as natural bio-resources, preference for bioeconomy development, access and development of technological innovations and maturity level. A summarised list of initiatives and action plans associated with each of the EU member states is presented as a part of the supplementary information.

Upon collation, analysis and categorisation of these initiatives, the preference of these member states over the choice of feedstock, bio-refining technology, current and desired products/sector development and techno-economic or social optimisation route were identified and ranked. This information was used to calculate weighted scores called "preference scores" to specific (feedstock-conversion route-bio-product combinations, based on the preference demonstrated by the EU-collective bioeconomy strategies. These scores, (as a \% of total number of strategies), have been presented in Table 3. Information on most of the EU-relevant bioeconomy strategies and initiatives collated and analysed as a part of the second round of assessment, is presented in the supplementary section in Table S1. The outcomes of this second round of assessment have also been discussed further under Section 3.1. 
Table 3. EU value chain preference scores as a function of strategy type and nature (as a \% of total number of EU bioeconomy strategies).

\begin{tabular}{llc}
\hline \multicolumn{1}{c}{ Value Chains Targeted by the Strategies } & \multicolumn{1}{c}{ Strategy Type } & EU Chain Preference Scores \\
\hline Bio energy and fuel production & Renewable energy & 0.74 \\
Food and beverage production & Primary food production & 0.6 \\
Crop based primary production & Using waste and residue & 0.37 \\
Animal based primary products & Using waste and residue & 0.32 \\
Forest based primary production & Using waste and residue & 0.26 \\
Bio-based material and plastics & Products/Technology and research & 0.26 \\
Marine based primary production & Primary food production & 0.2 \\
Bio-based chemicals & Products/Technology and research & 0.21 \\
Bio-based construction and furniture & Common conversion & 0.2 \\
Biorefinery & Products/Technology and research & 0.2 \\
Cosmetics and health & Biomass conversion & 0.17 \\
\hline
\end{tabular}

\subsection{Value Chain Mapping}

Within the H2020 programme, an industrial value chain is defined as stages of value creation by enterprises and other organisations as part of the process of designing and delivering goods and services for their users [22]. Nevertheless, new and innovative value chains are not required to be novel value chains but can be seen as new combinations across value chains, an innovative technology/product brought from one sector or context into another resulting in a disruptive effect.

Value chain maps are a valuable, flexible and convenient tool to develop and analyse the scope and performance potential of a bio-based business model by breaking down the various process dynamics into logistics, sectors of application and embedded stakeholders. The strengths, weaknesses, costs and competition from other value chains in the production of specific commodities can be visualised via value chain maps. The next step in identifying such promising value chains is to understand the chain complexities via such a "mapping exercise".

In this study, the initial "cradle-to-grave" value chain mapping provides a generalised yet visual schematic of the dynamics including the resource flow and actors integrated within bio-based value-chains that have been chosen via the assessments above. For the selected and finalised list of bio-based value chains, the following chain characteristics are crucial and relevant to visualising their significance to a circular economy. The characteristics are as follows:

- Material/energy inputs and outputs, including potential products, co-products, waste and emissions;

- Sector-level contributions;

- Technology/conversion routes;

- Chain-actors or stakeholders linkages

- End-of life (variable) characteristics emphasising the fate of the outputs from each of the life cycle stages.

\section{Results and Discussions}

\subsection{Value Chain Selection}

A two-tier multi-criteria decision analysis was undertaken to identify and select the most promising value chains and the outcomes of this assessment have been presented in Table 4 .

Bio-plastics, bio-based solvents, bio-lubricants, fabrics and fine chemicals followed by bio-based insulation material were chosen to progress to a second round of assessment. Within the second round of assessment, they were subjected to a similar weighted scoring, set against a background of EU-wide bioeconomy initiative. This "bioeconomy preference score" is primarily based on the target-feedstock and technology preferences of the bioeconomy initiatives and other relevant sustainability schemes established/planned with an active interest to transform from a linear economy to circular bio-based economy. 
Table 4. Selection of bio-based value chains from first-round "multi-criteria" assessment.

\begin{tabular}{ccccc}
\hline Sector & Value Chain & Score & Rank & Status \\
\hline Chemical & Cellulose to bio-based solvents & 7.44 & 1 & Selected \\
Food Packaging & Starch to bio-plastics & 7.25 & 2 & Selected \\
Agriculture & Starch to bio-based mulch films & 6.62 & 3 & Selected \\
Fabrication & Starch to bioplastic framing material & 6.09 & 4 & Selected \\
Multiple sectors & Vegetable fats/plant lipids to bio-based lubricants & 5.50 & 5 & Selected \\
Textile & Cellulose to fabric & 5.50 & 6 & Selected \\
Chemical & Solid biomass to fine chemicals & 5.20 & 7 & Selected \\
Construction & Waste agri. biomass to insulation material & 4.78 & 8 & Selected \\
Food packaging & Wood/cellulose to plastic paper cups & 4.37 & 9 & - \\
Food packaging & Straw to food packaging & 4.31 & 10 & - \\
Construction & Solid biomass to wood-plastic composite & 4.00 & 11 & - \\
Agriculture & Algal polysaccharides to phytoprotectives & 3.91 & 12 & - \\
\hline
\end{tabular}

In terms of feedstock preference, EU member states seemed to possess a clear strategy on utilising feedstock generated locally or nationally with minimal logistics and not demanding an additional stream (land-conversion)/infrastructure for feedstock generation (in other words, use excess and residual biomass). As a result, a majority of the initiatives highlight a feedstock preference in the following order: agricultural $(63 \%)$, forestry $(35 \%)$, waste stream (organic waste from domestic and commercial waste) (25\%). In terms of initiatives, there are those that either focus on pursuing innovative technology routes or prefer a combined approach to utilising biomass with innovative biomass transformation technologies. Preference for bio-based value chains based on the nature and goal of the initiatives assessed as a part of this study was identified and ranked in Table 5.

Table 5. Selection of value chains from a second round of "initiatives-based preference" assessment.

\begin{tabular}{|c|c|c|c|c|c|}
\hline Sector & Value Chain & $\begin{array}{l}\text { EU Chain } \\
\text { Preference } \\
\text { Scores }\end{array}$ & $\begin{array}{l}\text { Final } \\
\text { Score }\end{array}$ & Rank & Status \\
\hline Food Packaging & Starch to bio-plastics & 0.63 & 4.57 & 1 & Selected \\
\hline Agriculture & Starch to bio mulch films & 0.63 & 4.17 & 2 & Selected \\
\hline Fabrication & Starch to frame material & 0.63 & 3.84 & 3 & Selected \\
\hline Chemicals & Cellulose to bio-based solvents & 0.47 & 3.50 & 4 & Selected \\
\hline Multiple sectors & Vegetable fats/plant lipids to bio-based lubricants & 0.58 & 3.19 & 5 & Selected \\
\hline Construction & Waste agri. biomass to insulation material & 0.57 & 2.72 & 7 & - \\
\hline Textile & Cellulose to fabric & 0.31 & 1.71 & 8 & - \\
\hline
\end{tabular}

It is evident that there is a greater emphasis on development and exploitation of bio-based chemicals and bio-plastics in the conceived bioeconomy agenda and the existing bio-based infrastructure. There is a huge array of bioplastics, classified under roughly 10 categories, that are prevalent worldwide [36]. Currently, there is a focus on bioplastics that can be synthesised from one important feedstock, starch. This is due to the current availability of a mature and commercial conversion route that provides a feasible solution to existing "plastic waste management issues". In addition to this, the multi-functionality of bioplastic under study (PLA synthesised from starch), which (in combination with other polymers) may be utilised to create mulch films, disposable cutleries, framing materials and fibres defines its suitability to address the current challenges facing our transition to a fully-functional bioeconomy. Similarly, bio-based chemicals such as solvents, lubricants, dyes and pigments offer a greener and relatively low-environmental impact alternatives to their conventional counterparts facing restrictions of use from regulatory bodies such as REACH (Registration, Evaluation, Authorisation and Restriction of Chemicals) and ECHA (European Chemicals Agency) [37]. In addition to their lessened impact in terms of eco and human toxicity, their promising potential to create opportunities for socio-economic growth and reduce dependence on non-renewable resources creates a sustainable pathway for development. The construction sector is one of the biggest 
contributors of landfill waste in the EU owing to the design flaws in the product. Construction materials (particularly contemporary insulation material) are seldom created for any kind of responsible end-of-life management [38].

In view of the commercial, environmental and socio-economic potential identified from the value chains selected from the second round of assessment, they were adopted for an elaborate value-chain mapping in the Section 3.2.

\subsection{Value Chain Mapping—Case Studies}

The five bio-based value chains chosen from the second round of assessment have been adopted to be mapped for full (general) coverage of the resource flows, technology/conversion routes employed, the various stakeholders and the fate of the products or the other waste streams that may result from the value chain. These schematics have been presented in Figures 6-9. 


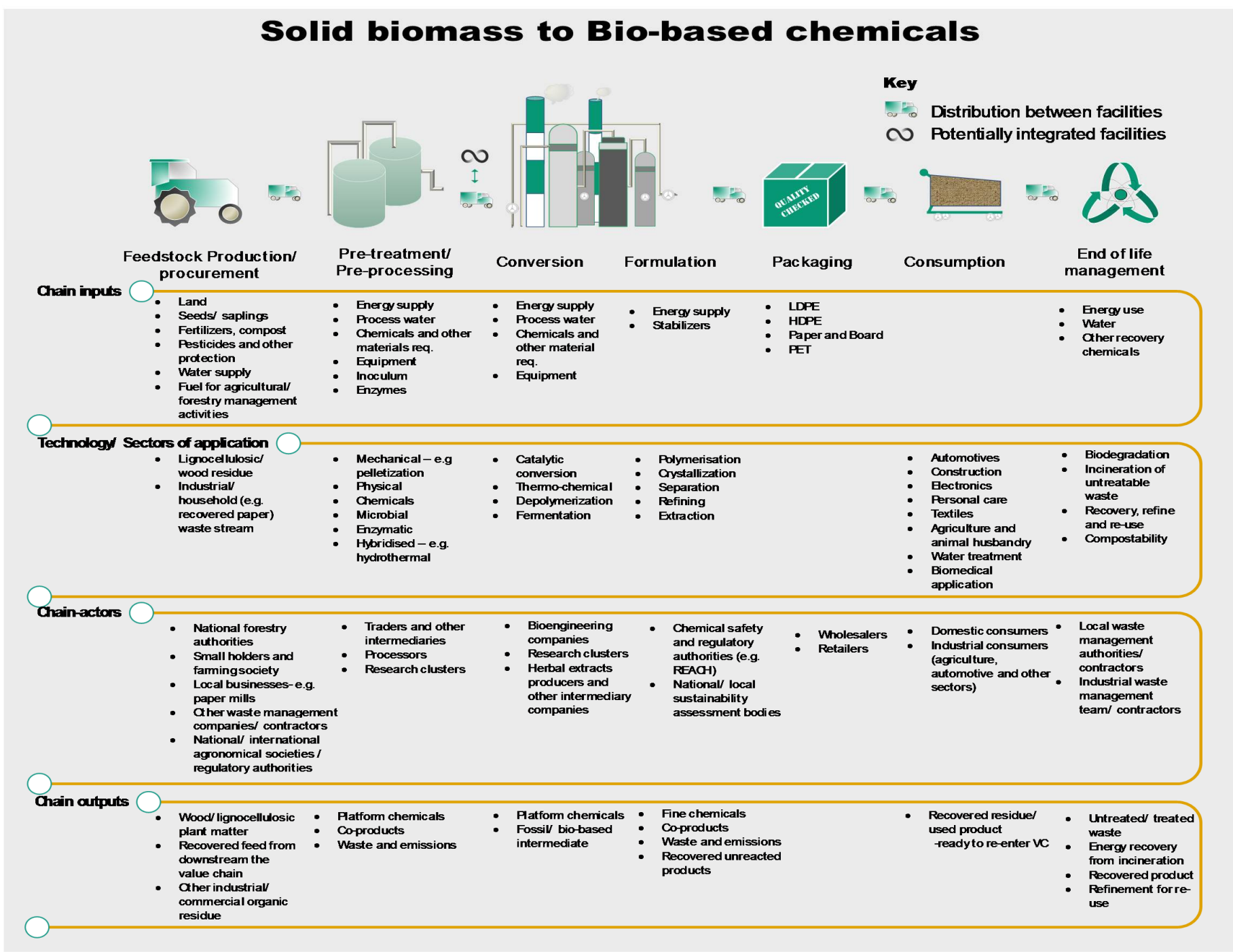

Figure 6. Value chains for solid biomass to bio-based chemicals, mapped for material flow, technology routes and stakeholders. 


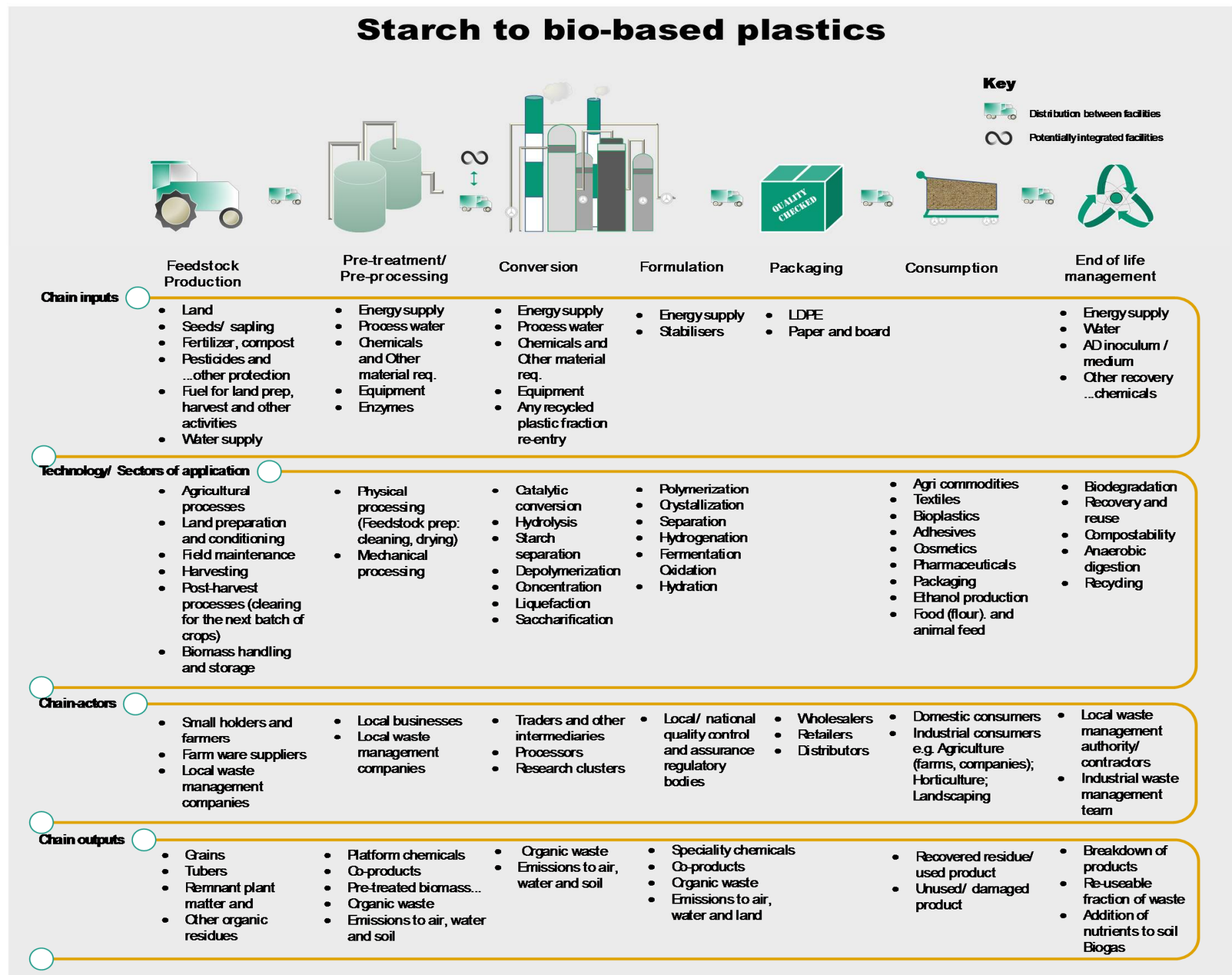

Figure 7. Value chains for starch to bio-based plastics, mapped for material flow, technology routes and stakeholders. 


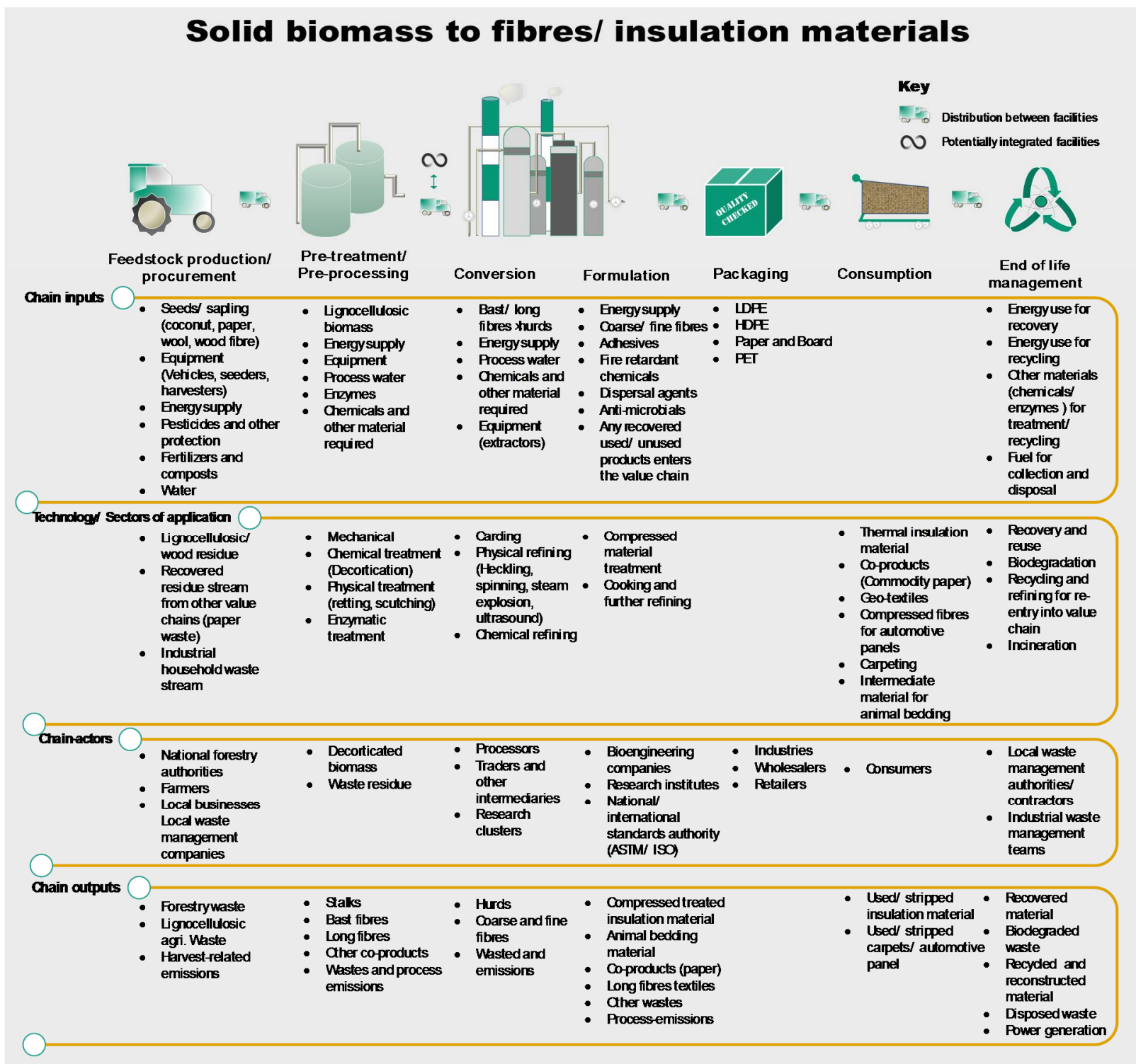

Figure 8. Value chains for solid biomass to insulation material, mapped for material flow, technology routes and stakeholders. 


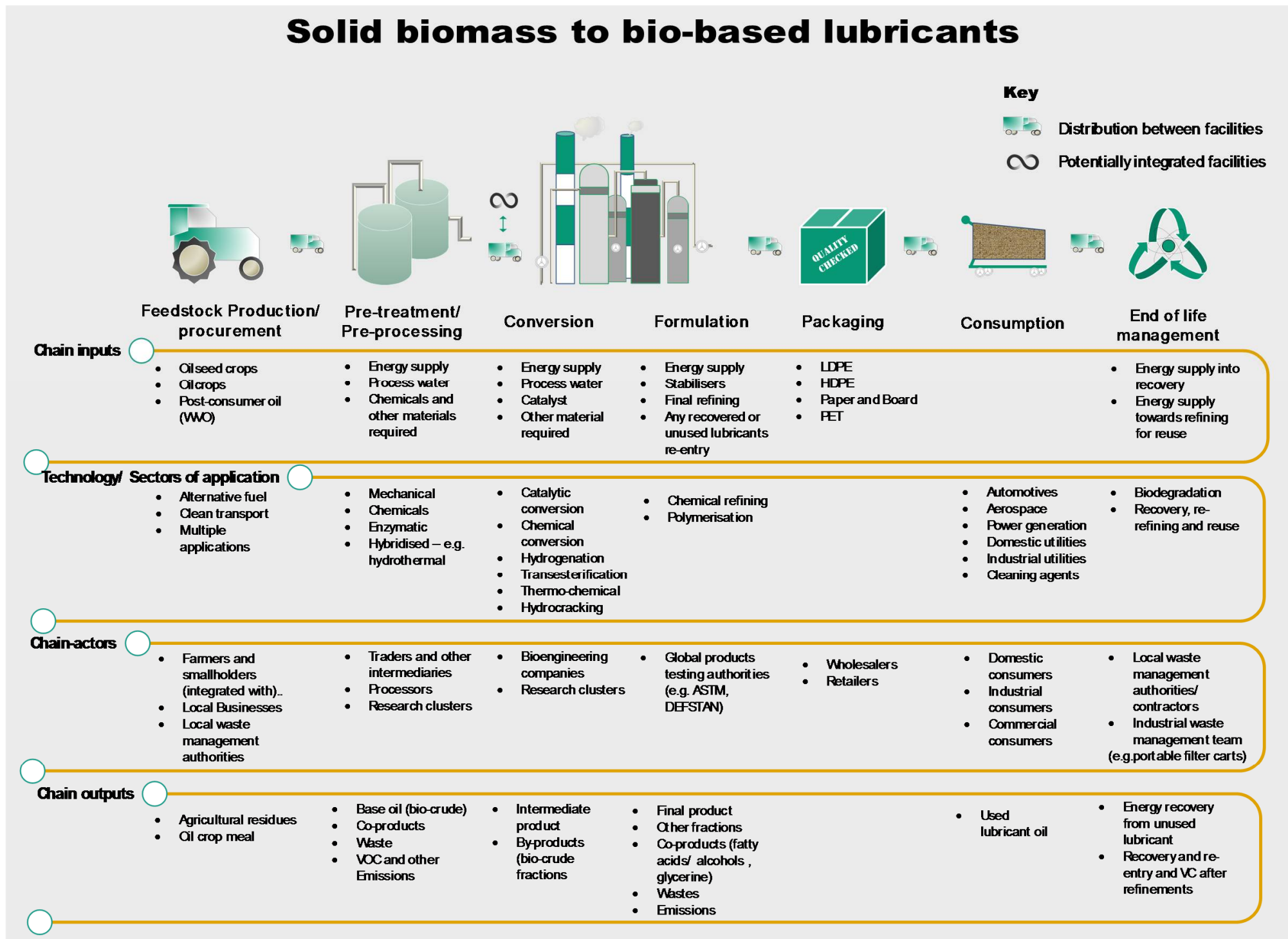

Figure 9. Value chains for solid biomass to bio-based lubricants, mapped for material flow, technology routes and stakeholders. 


\subsubsection{Bio-Based Chemicals}

The market for bio-based chemicals in general is worth $\$ 6$ billion and at a projected annual growth rate of $16.16 \%$, the market is expected to reach $\$ 27$ billion by 2025 [39]. Bio-based chemicals include a broad spectrum of products, which may be classified as commodity chemicals, intermediate chemicals and specialty chemicals, based on their application. Commodity chemicals refer to the "high volume-low value" products, sourced from biomass (but not restricted to), such as fatty acids, methyl esters and alcohols. Intermediate products refer to the refined sugar complexes, basic polymers, pigments/dyes, plant oils and other types of starches. Specialty chemicals, synthesised either independently from plant or prepared from intermediate chemicals includes bio-based chemicals such as advanced polymer solvents and other preparations for final formulation in personal care products, pharmaceuticals, paint coatings, additives, domestic/industrial detergents and other applications.

In particular, bio-based solvents are broadly classified into plant-based alcohols, diols, organic acids, glycols and many more. From an economic perspective, according to the above mentioned report [39] the global bio-based solvent market was worth roughly 6 billion USD in December 2016 and it is currently projected to grow at a CAGR of $7.8 \%$, reaching 9 billion by 2024 . The versatility of bio-based chemicals, particularly bio-based solvents (for example, in pharmaceutical, cosmetics, agriculture, cleaning, printing inks and adhesive applications), and demand/room for innovation and product development, coupled with stringent regulations on hazardous pollutants released from the use of conventional chemicals have fostered increased research interest and financial investment via national programmes and government support. Moreover, the feedstock variety that can be used to generate a myriad of bio-based chemicals makes these value chains innovative and techno-economically viable, in addition to their improved environmental performance.

\subsubsection{Bioplastics}

The EU preference to develop a manageable and multifunctional bioplastic category for the commercial market stems from the rapid and unsustainable consumption of conventional plastics for a variety of purposes, at a global level [40]. In addition, the discovery of alarming levels of micro plastics in our food sourced from soil, water and sea, has led to the awareness of the interactions between plastic degradation and the environment (bioaccumulation) [41]. This is evident in a number of initiatives, listed in the supplementary information, that all target withdrawal from fossil-based resources over the next decade with particular focus on energy and plastic consumption. Unlike a decade ago, modern bioplastics are catching up with bio-based solvents in terms of multi-sectoral application (including packaging, agriculture, cosmetics, electronics, construction and automotive) [36]. Evidence of encouragement of bio-based product development and growth can be seen from a plenary meeting of the European parliament that voted in favour of "biodegradable mulch films" during the revision of EU Fertiliser Regulation [42] and a recent increase in "big brands" adopting bio-plastics to appeal to their prominent (high spending power coupled with relatively high environmental awareness) consumer base [43].

\subsubsection{Other Bio-Based Products}

Bio-lubricants, predominantly synthesised from oil crops, find application in the domestic, industrial, automotive and aviation industry. Among the $220 \mathrm{EU}-28$ biorefineries assessed as a part of the study undertaken by the Bio-based Industries Consortium and Nova Institute (Figure 3), 20\% are dedicated to the manufacture of oleochemical from plant-derived fats. Environmental concerns and strict standards for management of leakage, maintenance and disposal of unused fossil-derived lubricants provide evidence for the growth and development of this sector. A EU-H2020 funded project entitled FIRST2RUN [44] is dedicated to the identification and development of integrated bio refineries that utilise low-input, under-utilised oil crops, grown in marginal lands to synthesise bio-lubricants and bioplastics from vegetable oil. Besides valorisation of marginal lands and low-input biomass, 
this project envisages the capability of such a value chain to create a skilled labour pool, generate other bio-based products and energy (composting unused parts of the plants), thereby revitalising the local economy.

Agricultural waste transformed into green, low-environmental impact insulation material was the conventional technology until the discovery of fossil resources, which gave rise to relatively inexpensive polymers and materials (e.g., polyurethane, mineral wool). However, some environmental and human health concerns are associated with these insulation materials (from long-term release of aerosols and vapour) such as respiratory issues and eye and skin irritation, particularly in the case of foam insulations. Natural fibre insulation such as cotton wool and wood fibre boards have been identified to perform similarly to their petro-derived counterparts and are particularly advantageous with regards to complying with any environmental building certification schemes [45]. Bio-based binders and other additives, such as polylactic acids (PLA) and polyhydroxyalkanoates (PHA) generated from other starch-based value chains, may be utilised in the preparation of these insulation materials. Dry lignocellulosic biomass can also be processed into compressed fibres for dashboard panels, geotextiles and animal bedding [46].

Limitations: MCDA can be a valuable tool, however, there are a few concerns when it is applied to immensely complex systems. When a process system involves social interactions such as producers, regulatory authorities and consumers, it becomes challenging to call one perspective as more important than the other. MCDA is also capable of overlooking or under-representing some key factors within a complex value chain. An essential and independently functional element within a bio-based value chain, eco-system services, is one such example. It is essential to be able to apply MCDA for smaller scale analysis to be able to predict all possible determinants of a particular chain-stage prior to its broader application. However, this can be time-consuming. Input/output (IO) analyses, which is a methodology that involves monitoring the sectoral trade data to quantify the complex interactions between the different nodes of a given value chain may also be utilised to study the dynamics of a value chains in real-time. However, its data needs depend on statistical information drawn from datasets published by government and international authorities (UN-FAOSTAT, EUROSTAT) [47] and the data may not always be available. Besides being data intensive, it may not always be possible to derive data for bio-based value chains based in rural communities, with IO methodology.

Value chain maps can be laborious and time-consuming to develop, depending on the complexity of the value chain under analysis. The map is only an informative tool for the visualisation of bio-based business models, identification of market opportunities and the scope of the value chain. It may not be able to highlight any changes in the dynamics associated with the factors (chain actors, inputs/outputs and technology routes) presented in the chain.

For this study, the mapping has been carried out to highlight, in general, probable material, wastes/emissions, conversion/refining routes associated with a given feedstock and end bio-product synthesised from it. These maps do not provide explicit information on coverage of these value chains by specific sustainability schemes/certification programmes as there are diverse products and co-products that could be produced as a part of the value chain. To establish this level of detail, the goal, scope and the product of analysis would have to be established beforehand.

\subsection{Gaps and Challenges That Can Be Addressed}

From having undertaken the multi-criteria decision analysis, a number of key aspects associated with the bio-based business models were brought into consideration, out of which, only a few general criteria were chosen as the selection criteria. Some of the key gaps and challenges that are addressed in this section were drawn based on our analysis and the mapping exercise on the overall. These are some key hurdles faced by existing and new bio-based business models in the current context of our transition to a bio-based economy. These points have been highlighted to encourage holistic systems thinking, starting from the feedstock procurement stage, through product design, which influences the final product cost up to the need for a dedicated end-of life management infrastructure which 
has an influence on public perception of bio-based products. Such systems thinking will encourage streamlining the innovation, processes and delivery of an incredibly complex bio-based value chains. Application of systems thinking can be customised to the practices in other non-bio-based sectors thereby facilitating our transition to a fully-functional circular economy.

"Food vs. non-food bio products" conflict: We live in an era of a global lack of food security, the supply chain of which alone is highly complex and fraught with unforeseeable risks such as crop failure from climate change or geo-political instability. To add to this, use of agro-food based biomass as the starting feedstock not only puts the bio-based business model at risk but also invites "food vs. bio-based products" conflict, undermining the sustainability characteristics of a bio-based value chain. However, substituting primarily food-based feedstock with waste-based feedstock or by-products would incorporate material circularity e.g., starch rich feedstock can be drawn from food retailers and food processing industries by using vegetable peels instead of starch rich crops. This strategy not only encourages waste valorisation but also reduces both the risks involved and the dependence of bio-based industries on the primary food supply chains.

Feedstock costs: Biomass may seem economically unfeasible compared to cheap petroleum feedstocks and their intermediates. The cost of feedstock which in turn is influenced by its supply/demand ratio in the commercial market makes it even more difficult for bio-based business models to increase profit margins and sometimes to breakeven. However, encouragement and development of innovative multi-functional bio refineries that are capable of utilising low-value, low-cost and waste biomass can prove to be an ideal alternative; such biorefineries must also be able to transform such waste feedstock into product designs that can be disassembled during their end-of-life with the product components being re-circularised back into the manufacturing loop. Re-incorporation of material can have long-term economic benefits to such business models, in addition maintaining the value of all the first-chain process inputs.

Supply risks: The seasonal nature of the biomass supply stemming from the cultivation time-span of biomass is an issue. However, further challenges posed to cross-border biomass supply from climate change, diminishing ecosystem services due to human intervention (e.g., intensive farming), variable food/biomass demand, geopolitical instabilities and social ethical concerns also undermine the "sustainable" characteristics of a bio-based value chains. It is therefore essential to encourage biorefinery and business models that are built on pre-established climate change resilient but low-demand biomass (e.g., millet and sorghum in Africa). From a cost perspective, their low demand reduces biomass costs, from a socio-economic perspective, accessing the knowledge pool of the local rural communities can be mutually beneficial via opportunities for rural development and encourages their interest in maintaining the local ecosystem services.

Interconnectedness of value chains: Uneven distribution or complete lack of technological readiness for a multi-regional/local value chain to be established is a key hurdle in transformation to a bio-based economy. This requires creation of awareness and a strong social connection between inter-chain stakeholders to encourage technological and operational coherence. The thought-process among the different chain actors (particularly among those involved between the feedstock procurement to packaging stage) has to be parallel with each other. Family businesses embed such wider thoughtful thinking and are mostly successful in staying established on a long-term, despite various external shocks, particularly from low-demand, inflation, etc. The key aspect to note is the trust developed with fellow stakeholders and customers with the consistency and quality of product. Occasional lack of co-operation due to process-level disparities between the embedded stakeholders of the value chains could be overcome via the establishment of national standards, covering stakeholders embedded in a value chain, with standardised templates for recording, reporting and communicating information.

Penetration of non-bio-based value chains: A recent shift in consumer behaviour, challenges to penetrating non-bio-based value chains (existing fossil-based supply chains) owing to consumer perception of "brand-value" and relatively cheaper products need to be considered. However, the trend 
is changing as there is a growing demand among consumers in small businesses owing to the "trust" factor that they are mainly passion driven rather than profit-driven [48].

Public perception of bio-based products: According to a review of various reports by Spatial Foresight, (2017), the general public's perception of bio-based products are highly variable [3]. As much as there is keenness to switch to bio-based products owing to their overall environmental benefits, the sporadic market supply, the expensive nature of such products and sometimes, limited functionality and durability of the bio-based products seem to hinder their acceptance. For members of the public who choose to opt for a more sustainable life, the existing product end-of-life management infrastructure is partially to fully unsuitable to pursue a circular waste management practice, leading to an overall skepticism. Therefore, a holistic approach is needed in our transformation to not only a bio-based economy but also to a circular economy.

"Top-down" and "bottom-up" initiatives: Stronger policy-level improvisation via "top-down" approaches drive chain-actors to encourage good practice such as producer responsibility (e.g., packaging industry) and deploy "re-direct used material" strategies. Similarly, "bottom-up" approaches, such as altering consumer behaviour via responsible and innovative retail design and practices, must also be devised. This may also include incentives/loyalty schemes for consumers who opt for bio-based products that upon consumption can be recovered and re-introduced into another product.

\section{Conclusions}

The purpose of this paper is to provide a methodology to assess existing or novel bio-based value chains from key angles that are of significance to our journey to attaining a fully functional bio-based circular economy. Due to the limited time and resources, it is essential to distinguish the most promising bio-based business model from the rest, and that is precisely what this paper, with its methodology suggests. EU-based bioeconomy and bio-based value chains are diverse in nature and are not restricted to those value chains that have been considered in this study. The preliminary list of 12 value chains was selected based on their relevance and significance to the bioeconomy, their current activity level/contribution and coverage by various sustainability and certification schemes. These bio-based value chains have been selected to ensure the representation of EU's diverse bio-based value chains in addition to their potential to address the key environmental, techno-economic and socio-economic threats and challenges faced globally. The value chains were selected in two-steps via multi-criteria decision analysis (MCDA), wherein the first step, the preliminary value chains were ranked by placing them against a back drop of five key selection criteria in the current context: feedstock variability; EU feedstock preference; variety of end-of-life options; multisector application and multi-regional supply chains. This step led to the identification of eight bio-based value chains which were subjected to a second round of assessment where five out of the eight value chains showed a promising interest/inclination for bioeconomic development. For the selected five bio-based value chains which included starch to bio-plastics, starch to bio mulch films, starch to frame material, cellulose to bio-based solvents, vegetable fats/plant lipids to bio-based lubricants, elaborate value chain maps were developed to demonstrate the highly informative nature of this tool and its crucial role in understanding the complex interactions among the various process stages, associated processes and stakeholders within a more complex value chain.

Value chain maps provide valuable insight into the integrated activities, actors and technology, in addition to the material flow, and have provided a foresight of the scope and qualitative performance potential (in socio-economic and environmental terms) within each of the life cycle stages. Inability to acquire real-time information from any changes to the process dynamics may be a limitation. However, for a preliminary assessment, value-chain mapping provides an overall breakdown of the various elements presented above. The methodology prescribed in this paper not only helps understand the embedded complexities and overcome them within bio-based value chains but are also equally applicable to complex non-bio-based supply chains that foresee a transformation by closing their loop 
to encourage product and process circularity. Overall, the suggested method could be used by policy makers, investors, business groups and economists to understand the interdependencies among the various embedded chain-actors, dependence of the chain on material consumption and the various technology routes available for innovative and sustainable production of bio-based products that can potentially replace high-impact fossil-derived products.

Supplementary Materials: The following are available online at http:/ /www.mdpi.com/2071-1050/10/6/1695/ s1, Table S1: Bioeconomy initiatives and strategies analysed for the second round of the value chain assessment and selection.

Author Contributions: The concept of analysis, methodology, data acquisition and interpretation and development of the manuscript were all jointly undertaken by K.L., L.L. and L.S.

Funding: The contents of the paper are a part of the findings of the project STAR-ProBio. STAR-ProBio has received funding from the European Union's Horizon 2020 program and innovation programme under grant agreement No. 727740, Work Programme BB-01-2016: Sustainability schemes for the bio-based economy.

Acknowledgments: We would like to convey a special thanks to our partners from the Agricultural University of Athens, Greece, Deutsches Biomasseforschungszentrum, Germany, SQ Consult, Spain and the University of Bologna, Italy who contributed to the research undertaken in this paper.

Conflicts of Interest: The authors declare no conflict of interest. Re-use of information contained in this document for commercial and/or non-commercial purposes is authorised and free of charge, on the conditions of acknowledgement by the re-user of the source of the document, not distorting the original meaning or message of the document and the non-liability of the STAR-ProBio consortium and / or partners for any consequence stemming from the re-use. The STAR-ProBio consortium does not accept responsibility for the consequences, errors or omissions herein enclosed. This document is subject to updates, revisions and extensions by the STAR-ProBio consortium. Questions and comments should be addressed to: http:/ /www.star-probio.eu/contact-us/.

\section{References}

1. European Commission. Towards a Circular Economy. Available online: https://ec.europa.eu/commission/ priorities/jobs-growth-and-investment/towards-circular-economy_en (accessed on 28 October 2017).

2. Jurgilevich, A.; Birge, T.; Kentala-Lehtonen, J.; Korhonen-Kurki, K.; Pietikäinen, J.; Saikku, L.; Schösler, H. Transition towards Circular Economy in the Food System. Sustainability 2016, 8, 69. [CrossRef]

3. Spatial Foresight; SWECO; ÖIR; Nordregio; Berman Group; Infyde. Bioeconomy Development in EU Regions. Mapping of EU Member States'/regions' Research and Innovation Plans \& Strategies for Smart Specialisation (RIS3) on Bioeconomy for 2014-2020; DG Research \& Innovation, European Commission: Brussels, Belgium, 2017.

4. D'Amato, D.; Droste, N.; Allen, B.; Kettunen, M.; Lähtinen, K.; Korhonen, J.; Leskinen, P.; Matthies, B.D.; Toppinen, A. Green, circular, bio economy: A comparative analysis of sustainability avenues. J. Clean. Prod. 2017, 168, 716-734. [CrossRef]

5. Lieder, M.; Rashid, A. Towards circular economy implementation: A comprehensive review in context of manufacturing industry. J. Clean. Prod. 2016, 115, 36-51. [CrossRef]

6. Frank, D. The Bioeconomy is Much More than a Circular Economy. Available online: https://www.brainbiotech.de/en/blickwinkel/circular/the-bioeconomy-is-much-more-than-a-circular-economy / (accessed on 8 May 2018).

7. Geels, D.I.F.W. The dynamics of transitions in socio-technical systems: A multi-level analysis of the transition pathway from horse-drawn carriages to automobiles (1860-1930). Technol. Anal. Strateg. Manag. 2005, 17, 445-476. [CrossRef]

8. Shove, E. Putting practice into policy: Reconfiguring questions of consumption and climate change. Contemp. Soc. Sci. 2014, 9, 415-429. [CrossRef]

9. Honegger, M.; Reiner, D. The political economy of negative emissions technologies: Consequences for international policy design. Clim. Policy 2018, 18, 306-321. [CrossRef]

10. Tukker, A. Product services for a resource-efficient and circular economy-A review. J. Clean. Prod. 2015, 97, 76-91. [CrossRef]

11. Pan, S.-Y.; Du, M.A.; Huang, I.-T.; Liu, I.-H.; Chang, E.-E.; Chiang, P.-C. Strategies on implementation of waste-to-energy (WTE) supply chain for circular economy system: A review. J. Clean. Prod. 2015, 108, 409-421. [CrossRef] 
12. Greene, J.P. Introduction to Sustainability. In Sustainable Plastics; John Wiley \& Sons, Inc.: Hoboken, NJ, USA, 2014; pp. 1-14. ISBN 978-1-118-89959-5.

13. Brosowski, A.; Thrän, D.; Mantau, U.; Mahro, B.; Erdmann, G.; Adler, P.; Stinner, W.; Reinhold, G.; Hering, T.; Blanke, C. A review of biomass potential and current utilisation-Status quo for 93 biogenic wastes and residues in Germany. Biomass Bioenergy 2016, 95, 257-272. [CrossRef]

14. Pick, D.; Dieterich, M.; Heintschel, S. Biogas Production Potential from Economically Usable Green Waste. Sustainability 2012, 4, 682-702. [CrossRef]

15. Gurría, P.; Ronzon, T.; Tamosiunas, S.; López, R.; García Condado, S.; Guillén, J.; Cazzaniga, N.; Jonsson, R.; Banja, M.; Fiore, G.; et al. Biomass Flows in the European Union; European Commission Joint Research Centre: Seville, Spain, 2017.

16. Parisi, C.; Ronzon, T. A Global View of Bio-Based Industries: Benchmarking and Monitoring Their Economic Importance and Future Developments; JRC Technical Reports; European Commission: Brussels, Belgium, 2016.

17. Bio-Based Industries Consortium Mapping European Biorefineries | Bio-Based Industries Consortium. Available online: http://biconsortium.eu/news/mapping-european-biorefineries (accessed on 1 December 2017).

18. Fehrenback, H.; Köppen, S.; Kauertz, B.; Detzel, A.; Wellenreuther, F.; Brietmayer, E.; Essel, R.; Carus, M.; Kay, S.; Wern, B.; et al. Biomass Cascades: Increasing Resource Efficiency by Cascading Use of Biomass-From Theory to Practice; German Environmental Agency: Heidelberg, Germany, 2017; p. 29.

19. Myllyviita, T.; Holma, A.; Antikainen, R.; Lähtinen, K.; Leskinen, P. Assessing environmental impacts of biomass production chains-Application of life cycle assessment (LCA) and multi-criteria decision analysis (MCDA). J. Clean. Prod. 2012, 29-30, 238-245. [CrossRef]

20. Zanghelini, G.M.; Cherubini, E.; Soares, S.R. How Multi-Criteria Decision Analysis (MCDA) is aiding Life Cycle Assessment (LCA) in results interpretation. J. Clean. Prod. 2018, 172, 609-622. [CrossRef]

21. European Parliament. Circular Economy Package: Four Legislative Proposals on Waste; European Parliamentary Research Service: Brussels, Belgium, 2016.

22. European Commission. Bioeconomy Strategy: Innovating for Sustainable Growth: A Bioeconomy for Europe; European Commission: Brussels, Belgium, 2012.

23. European Commission. 2030 Energy Strategy. Available online: https://ec.europa.eu/energy/en/topics/ energy-strategy-and-energy-union/2030-energy-strateg (accessed on 5 January 2018).

24. Meyer-Kohlstock, D.; Schmitz, T.; Kraft, E. Organic Waste for Compost and Biochar in the EU: Mobilizing the Potential. Resources 2015, 4, 457-475. [CrossRef]

25. STAR-ProBio. Report on Identified Environmental, Social and Economic Criteria/Indicators/Requirements and Related "Gap Analysis; STAR-ProBio: York, UK, 2017.

26. Hennig, C.; Brosowski, A.; Majer, S. Sustainable feedstock potential-A limitation for the bio-based economy? J. Clean. Prod. 2016, 123, 200-202. [CrossRef]

27. Budzinski, M.; Bezama, A.; Thrän, D. Monitoring the progress towards bioeconomy using multi-regional input-output analysis: The example of wood use in Germany. J. Clean. Prod. 2017, 161, 1-11. [CrossRef]

28. Pagotto, M.; Halog, A. Towards a Circular Economy in Australian Agri-food Industry: An Application of Input-Output Oriented Approaches for Analyzing Resource Efficiency and Competitiveness Potential. J. Ind. Ecol. 2016, 20, 1176-1186. [CrossRef]

29. CEN European Committee for Standardization. CEN/TS 16295:2012: Bio-Based Products. Requirements for Business-to-Consumer Communication and Claims. 2017. Available online: https://shop.bsigroup.com/ ProductDetail/ ?pid=000000000030330832 (accessed on 15 August 2017).

30. CEN European Committee for Standardization. BS EN 16751:2016: Bio-Based Product. Sustainable Criteria. 2016. Available online: https:/ / standards.cen.eu/dyn/www/f?p=204:22:0::::FSP_ORG_ID,FSP_LANG_ID: 874780,25\&cs=1D63BAA7EABE56EB230DDAA05D6F2CE70 (accessed on 13 June 2017).

31. CEN European Committee for Standardization. PD CEN/TS 16398:2012: Plastics. Template for Reporting and Communication of Biobased Carbon Content and Recovery Options of Biopolymers and Bioplastics. Data Sheet. 2012. Available online: https:/ / shop.bsigroup.com/ProductDetail/?pid=000000000030258216 (accessed on 28 June 2017).

32. CEN European Committee for Standardization. Plastics. Determination of Bio-Based Carbon Content; CEN European Committee of Standardisation: Brussels, Belgium, 2011. 
33. CEN European Committee for Standardization. CEN/TC 411. Available online: https:/ / standards.cen.eu / dyn/www /f?p=204:7:0::::FSP_ORG_ID:874780\&cs=112703B035FC937E906D8EFA5DA87FAB8 (accessed on 11 January 2018).

34. Keegan, D.; Kretschmer, B.; Elbersen, B.; Panoutsou, C. Cascading use: A systematic approach to biomass beyond the energy sector. Biofuels Bioprod. Biorefin. 2013, 7, 193-206. [CrossRef]

35. Blennow, K.; Persson, E.; Lindner, M.; Faias, S.P.; Hanewinkel, M. Forest owner motivations and attitudes towards supplying biomass for energy in Europe. Biomass Bioenergy 2014, 67, 223-230. [CrossRef]

36. Greene, J.P. Sustainable Plastic Products. In Sustainable Plastics; John Wiley \& Sons, Inc.: Hoboken, NJ, USA, 2014; pp. 145-186, ISBN 978-1-118-89959-5.

37. Dubois, J.-L. Requirements for the development of a bioeconomy for chemicals. Curr. Opin. Environ. Sustain. 2011, 3, 11-14. [CrossRef]

38. Akanbi, L.A.; Oyedele, L.O.; Akinade, O.O.; Ajayi, A.O.; Davila Delgado, M.; Bilal, M.; Bello, S.A. Salvaging building materials in a circular economy: A BIM-based whole-life performance estimator. Resour. Conserv. Recycl. 2018, 129, 175-186. [CrossRef]

39. Zion Market Research Global Bio-Solvents Market Will Reach USD 9.43 Billion by 2022: Zion Market Research. Available online: http://globenewswire.com/news-release/2017/09/22/1131467/0/en/ Global-Bio-Solvents-Market-Will-Reach-USD-9-43-Billion-by-2022-Zion-Market-Research.html (accessed on 6 November 2017).

40. Greene, J.P. Biobased and Biodegradable Polymers. In Sustainable Plastics; John Wiley \& Sons, Inc.: Hoboken, NJ, USA, 2014; pp. 71-106, ISBN 978-1-118-89959-5.

41. Carrington, D. Plastic fibres found in tap water around the world, study reveals. The Guardian, 6 September 2017.

42. Schwede, K. European Parliament Supports Use of Biodegradable Mulch Films. Available online: http: / / www.european-bioplastics.org/european-parliament-supports-use-of-biodegradable-mulch-films / (accessed on 6 November 2017).

43. European Bioplastics. Bioplastics: Facts and Figures; European Bioplastics: Berlin, Germany, 2016.

44. Bio-based Industries Consortium FIRST2RUN I Bio-Based Industries Consortium. Available online: http: / / biconsortium.eu/library/case-studies/first2run (accessed on 14 January 2018).

45. Carus, M.; Eder, A.; Dammer, L.; Korte, K.; Scholz, L.; Essel, R.; Breitmayer, E.; Barth, M. WPC/NFC Market Study 2014; Wood-Plastic Composites (WPC) and Natural Fibre Composites (NFC); Nova-Institut GmbH: Hürth, Germany, 2014.

46. Alkhagen, M.; Samuelsson, A.; Aldaeus, F.; Gimaker, M.; Ostmark, E.; Swerin, A. Roadmap 2015-2025: Textile Material from Cellulose; The RISE Research Institute of Sweden: Stockholm, Sweden, 2015.

47. You, F.; Tao, L.; Graziano, D.J.; Snyder, S.W. Optimal design of sustainable cellulosic biofuel supply chains: Multiobjective optimization coupled with life cycle assessment and input-output analysis. AIChE J. 2012, 58, 1157-1180. [CrossRef]

48. Daneshkhu, S. Consumer Goods: Big Brands Battle with the 'Little Guys'. Available online: https://www.ft. com/content/4aa58b22-1a81-11e8-aaca-4574d7dabfb6 (accessed on 3 May 2018).

(c) 2018 by the authors. Licensee MDPI, Basel, Switzerland. This article is an open access article distributed under the terms and conditions of the Creative Commons Attribution (CC BY) license (http:/ / creativecommons.org/licenses/by/4.0/). 